\title{
What does the duration of belonging tell us about the temporal self?
}

DOI:

10.1177/0961463X16656853

\section{Document Version}

Accepted author manuscript

Link to publication record in Manchester Research Explorer

\section{Citation for published version (APA):}

May, V. (2016). What does the duration of belonging tell us about the temporal self? Time and Society, 25(3), 634651. https://doi.org/10.1177/0961463X16656853

\section{Published in:}

Time and Society

\section{Citing this paper}

Please note that where the full-text provided on Manchester Research Explorer is the Author Accepted Manuscript or Proof version this may differ from the final Published version. If citing, it is advised that you check and use the publisher's definitive version.

\section{General rights}

Copyright and moral rights for the publications made accessible in the Research Explorer are retained by the authors and/or other copyright owners and it is a condition of accessing publications that users recognise and abide by the legal requirements associated with these rights.

\section{Takedown policy}

If you believe that this document breaches copyright please refer to the University of Manchester's Takedown Procedures [http://man.ac.uk/04Y6Bo] or contact uml.scholarlycommunications@manchester.ac.uk providing relevant details, so we can investigate your claim.

\section{OPEN ACCESS}




\section{What does the duration of belonging tell us about the temporal self?}

\section{Vanessa May}

\section{Abstract}

Belonging is a fundamentally temporal experience, yet there exists to date little research on belonging as a temporal phenomenon. This paper offers an important contribution to the literatures on belonging, time and the self by exploring how the experience of belonging is tethered to time. Focussing on the temporal dimensions of the interconnection between belonging and the self contributes to our understanding of how people experience time and construct a sense of self. The data comprise 62 accounts on belonging written by members of the Mass Observation Project's panel of volunteer writers residing in Great Britain. Two dimensions of duration are explored: first, enduring belonging compared to fleeting belonging and second, belonging that endures 'out of time'. In relation to the first dimension I argue that the duration of belonging aids in constructing a coherent self over time and thus speaks to a person's moral character. The second dimension of duration illustrates experiences of belonging that defy understandings of linear temporality and a singular self, thus demonstrating the fundamentally distributed nature of the self. Attending to the duration of belonging also adds to our empirical understanding of how time is experienced by people.

\section{Keywords}

Belonging, duration, time, self, narrative

Word count: 7786

\section{Introduction}


This paper is concerned with belonging as a temporal experience, that is, with how people experience a sense of belonging in and through time, and how their experiences of the passage of time come to colour what belonging means to them. The interconnection between belonging and the self, and how attending to the temporal dimensions of this interconnection can help us better understand how people experience time and construct a sense of self, lie at the heart of this paper. These issues are explored with the help of data from the Mass Observation Project (MOP) comprising 62 accounts written by people aged between 20 and 91 living in Great Britain. Existing literature on belonging has identified that belonging is a dynamic experience, a trajectory through space and time that is sensitive to change (May, 2011: 372). The dimension of change that has hitherto been explored extensively by social scientists is the impact of geographical movement on belonging, most notably among transnational migrants (e.g., Ramírez, 2014; Binaisa, 2011; BönischBrednich and Trundle, 2010; Passerini et al., 2007; Golden, 2002; Fortier, 2000). The present paper is concerned with an aspect of change that has received less explicit attention from researchers, namely time and, more specifically, how people's experience of time intertwines with their sense of belonging. The MOP accounts, derived from a directive that asked people to reflect upon their changing experiences of belonging, offer prime material to explore the temporal nature of belonging in more depth.

The first section of the paper outlines what belonging consists of and why it is important to the self, followed by an exploration of theories of how time is experienced as duration and understood in the form of narrative, and of the significance of time and narrative for the self. I then go on to discuss the data and methods used in this paper, before moving on to explore the findings. The duration of belonging appears as the most significant temporal aspect in the MOP accounts, and two dimensions of duration are analysed: chronological duration and duration that is experienced 'out of time'. I argue that a sense of a coherent self is partly achieved by reference to the linear temporality of enduring experiences of belonging with people, particularly friends. These accounts lend support to the linear logic by which belonging tends to be depicted in research, namely as 
something that is built up over time. This is perhaps understandable given the predominance of the singular self in Western societies, a self that is constructed through narratives that adhere to rules of coherence and causality. However, the MOP writers also talk in some depth about inexplicable belongings that are experienced 'out of time' in ways that defy understandings of linear temporality and a singular self. Ultimately, the duration of belonging reflects the moral character of the self that is being narrated, and is able to shed light on the distributed nature of the self. Attending to the temporal dimensions of belonging also adds to our empirical understanding of how time is experienced by people.

\section{The importance of belonging to the self}

Belonging is here defined as a sense of ease a person can have with themselves and with their surroundings (May, 2011; Miller, 2003). Furthermore, belonging is the necessary scaffolding on which the interpersonally 'distributed self' is built, a self that is developed in and through social interaction and that remains 'enmeshed in a net of others' (Bruner, 1990: 106-107, 114; Mead, 1934). We are, in essence, social selves, and one of the ways in which this social dimension of the self becomes apparent is through a sense of connectedness or belonging to people, to places and to cultures (May, 2013). This sense of belonging guides how we act in the social world and helps inform with whom we form relationships, in which places we feel comfortable, and which types of activities we engage in.

Much of the belonging literature treats belonging as something that is anchored in particular territories. Belonging is thus delineated as a feeling of being 'at home' somewhere and a means through which people can claim inclusion in a particular society (Antonsich, 2010; Yuval-Davis, 2011). Numerous scholars have noted the need to use a temporal lens when exploring the construction of communities and national identity, that is, collective forms of belonging that are based on an 
interpretation of the past that is seen to inform 'who we are' (Monteiro, 2015; Bastian, 2014;

Golden, 2002; Cwerner, 2000; Taylor \& Wetherell, 1999). This linear logic of how collective forms of belonging are depicted as built over time, the result of ongoing power struggles and taking place within linear chronological time where the present supersedes the past, mirrors Western narratives of history as progression (e.g. Monteiro, 2015; Yuval-Davis, 2011; Fenster, 2004).

I wish to argue that there is insufficient theorisation of as well as empirical research on the temporality of belonging as experienced by individual persons. As with collective belonging, individual belonging tends to be depicted in a linear fashion as something that is built up over time and that is informed by past experiences. Though much of the research on belonging centres on changes in people's sense of belonging, as in the case of transnational migrants, the focus tends not to be on the necessary condition for change, namely time. In the present paper, I examine the temporal aspect of belonging as such and will come to argue that belonging is not merely experienced in relation to multiple sources, such as people, places and cultures, and on multiple scales from the micro to the macro (cf. Antonsich, 2010; Wood \& Waite, 2011), but also across multiple temporalities including linear and non-linear experiences of time. But before I turn to describe the data and findings of this paper, it is necessary to examine what theorists of time have to say about the human experience of time as duration, and the role that narrative plays in this.

\section{Time, self and narrative}

I have above established the important role that belonging plays in the construction of a self. Time and narrative are also crucial to our sense of self. Yet there is to my knowledge no literature that connects these different aspects of the self. Just as the belonging literature has little to say about how people experience belonging in and through time, the literature on temporal selves has not considered the importance of temporality for belonging. To put it another way, there is more to be 
said about how temporal experiences inform a person's sense of belonging and thus their sense of self.

To explore the relationship between belonging, time and the self, I utilise Bergson's work on duration as well as the literature on narrative temporal selves. Whereas universal time is depicted as going relentlessly forward at an unvarying pace, where one second is ostensibly the same as any other second, time as duration is time as experienced by humans, for example as passing quickly or slowly (Bergson, 1988[1896]; Flaherty, 1993; Flaherty, 2002). People thus experience time, not as a series of identical and faceless nows as measured by clocks, but from within the present where each moment is different and encompasses also past and future horizons, that is, 'the historical present of someone' (Muldoon, 2006: 195; Mead, 1932). Bergson differentiates between space/time on the one hand and duration as lived on the other. While space and time act as abstract frameworks that can be counted, duration as lived refers to the subjective experience of the passage of time and is characterised by quality, not quantity (Guerlac, 2006: 90). Duration refers to the intensity of experiences, where each moment is unique because it carries with it the history of all the moments that came before, and the unique situation in which the moment is experienced. Duration is in other words the subjective experience of time that always folds within it past experiences. Deleuze (1988: 52) interprets Bergson as saying that duration and memory are one and the same thing. Rather than viewing the past and the present as two successive moments, one following the other, duration allows us to see how the past and the present can coexist (Deleuze, 1988: 59-60) with the past enduring as a living past (Coleman, 2008).

Bergson (2001[1889]) notes that the difference between time, which is comprehended through the use of symbolic representation such as language and clocks, and duration, which refers to time as directly experienced, is reflected in the distinction between two modes of subjective experience. According to Bergson, time corresponds with 'a superficial self that conforms to social conventions and the pressures of language', while duration is linked to 'a passionate self, in touch 
with the heterogeneous real' (Guerlac, 2006: 70). I will return to this distinction in relation to the difference between two types of belonging: the first is experienced as linear chronological duration and follows the rules of narrative, depicting events as causally related, while the second is experienced 'out of time' and does not follow the same rules of coherence or linear temporality.

Bergson argues that we cannot think duration - the moment we start to think it, we change it into something else (Guerlac, 2006: 91). We can only think time that has passed, not the time we are living now. An important way that we come to understand time - or indeed any aspect of our experience - is through narrative (Ricoeur, 1981; Bruner, 1987). Narrative and temporality are also crucial elements of our sense of self, for it is by telling stories, to ourselves and to others, about where we come from, who we are and who we hope (or fear) to become (Sayer, 2004; Brockmeier, 2000) that we give shape to our sense of self. In telling these self-narratives, we usually follow key narrative 'rules', one of which is coherence (Øian, 2004; Becker, 1999). In other words, we tend to tell stories where $A$ leads to $B$, which in turn to leads to $C$ in a logical and recognisable fashion. This means that narratives allow us to convey a self that endures such that it is seemingly the logical result of our past experiences and maintains a core 'true' self that remains unchanged across time. Yet our narratives also tell of change over the lifecourse (Bamberg, 2012) and our selves lead 'a treacherous existence', constantly 'stitching back together ... those frayed parts of [ourselves] that time has rent asunder' (Chandler, 2000: 212). Indeed, in order to successfully attain personhood, we must fulfil the 'contradictory, but constitutive, obligations to both change and remain the same', and narrative is the 'dynamic glue' that holds 'the self together through time' (Chandler, 2000: 212, 215).

This sense of having a continuous and concrete identity across space and time is of fundamental importance in the construction of selves in Western cultures (Sayer, 2004: 80, 84; Bruner, 1987; Nelson, 2000; Chandler, 2000). A self that remained unchanged through time would be an impossibility, while a person who did not exhibit any self-sameness from one day to the next would not only be considered an oddity, but untrustworthy and lacking in moral fibre. In other 
words, presenting oneself as a coherent and continuous self is a crucial element in being able to claim a 'moral self'. Presenting one's self according to the cultural expectation of self-sameness is a way of signalling to others that one holds oneself accountable in light of shared social norms (May, 2008: 471). The coherence that people construct through their self-narratives is important also for social order and cohesion because it means that they can be expected to exhibit consistent characteristics over time and be held accountable by others for their past actions, something that would be impossible if their attitudes and preferences were constantly changing (Young, 1988: 12; Gergen \& Gergen, 1983; Chandler, 2000). A sense of enduring belonging, I will argue, is one way that allows us to experience and express a coherent and continuous self and is therefore positively evaluated. But, there are also other forms of temporal belonging that are experienced 'out of time'. These cannot be narrated using the same logic of linear time and progression but are no less potent or meaningful for that. I will also come to argue that studying temporal selves through the lens of the duration of belonging allows for a way of empirically exploring Bergson's rather abstract theories on duration, thus adding to our understanding of how time is experienced by people.

\section{Methods}

The Mass Observation Project (MOP), from which the data for this paper derive, is a writing project the aim of which is to construct an archive of everyday life in Britain with the help of a panel of volunteer writers (Sheridan, 1993). At any one time, this panel consists of around 500 writers, who three times a year receive a directive asking them to write about particular topics. The archive of responses is kept at the University of Sussex and is available to researchers upon application. In 2010 I commissioned a directive on belonging that asked Mass Observers to write about their experiences of belonging in relation to a range of sources, including people, places and culture, and to also reflect on instances when they have not belonged. Time was central to how Mass Observers were instructed to consider changes in their sense of belonging: 
Has your sense of belonging changed during your lifetime? Was there for example a place where you felt a sense of belonging, but where you no longer feel you belong, or vice versa? What do you think has caused these shifts?

MOP writers were also asked to compare, in the form of relational diagrams depicting concentric circles, their closest relationships at the time of writing and ten years previously, and similarly to compare a list of the places where they felt they belonged now and ten years ago. Writers were then asked to reflect upon any changes that had occurred and possible reasons for these.

The belonging directive received 185 responses, of which a subsample of 62 accounts has been chosen for analysis in the present paper. These 62 accounts are distinguished by the fact that the writers explicitly address the issue of time. All MOP writers are asked to include in their accounts the following basic information about themselves: age, gender, marital status, occupation and place of residence. Most, but not all, of the writers do provide this demographic information. The sample characteristics mirror those of the MOP panel overall in terms of gender, age, social class and ethnicity (cf. Kramer, 2011). The majority of the 62 writers are women $(\mathrm{N}=44)$ and the average age is 55 (the youngest writer being 20 and the oldest 91 years of age). The majority ( $\mathrm{N}=49$ ) work in or are retired from white-collar occupations ranging from teacher's assistant to company director, three have (had) blue-collar occupations, two are students, one is a housewife, two are off work due to long-term illness and four of the writers do not indicate their (former) occupation. I assume that all $62 \mathrm{MOP}$ writers are white because none of them mention their ethnicity - the majority ethnic group have this privilege of not noticing their ethnicity because it is unremarkable (e.g. Byrne, 2006). The same goes for sexuality: only two gay men mention their sexuality, the rest are assumed to be heterosexual.

The first step in the analysis was to roughly code the material in order to identify which topics were covered in relation to time. This was followed by grouping these themes under temporal headings, such as 'age', 'temporary belonging' and 'belonging in the past'. These were then further 
refined into analytical codes such as 'lifecourse', 'temporal location of belonging' and 'duration of belonging'. The analysis focused on the temporal words used to describe belonging (e.g. sudden, gradual, permanent, temporary), which temporal dimensions came to the fore in connection with which types of belonging, and how these experiences were evaluated. I compared men and women's accounts but could not discern any clear gendered differences in relation to the temporality of belonging. This is somewhat surprising given that men and women are purported to write self-narratives using different temporalities (Jelinek, 1986), but can perhaps be explained by the relatively small size of the sample. The issues of belonging across the lifetime and the temporal location of belonging are addressed in separate papers (May, N.d.a; May, N.d.b), while the present paper focuses on findings in relation to duration.

\section{Enduring belonging}

The theories on time discussed above tell us that experienced duration is a fundamental aspect of human time, which is rendered meaningful through the act of telling stories. The MOP writers were particularly concerned with the duration of what is perhaps the most fundamental form of belonging that we experience as social beings, namely relational belonging to family and friends. They contrasted relational belonging that stands the test of time with belonging that diminishes over time, and evaluated these differently.

Given the crucial role that family plays in our construction of a self (Mead, 1934; Bruner, 1990: 114) and the common Anglo-American saying that family is given (Spencer \& Pahl, 2006), it is perhaps not surprising that family of origin represents in the MOP accounts the gold standard of permanent relational belonging: 'Once a member of a family you belong for ever' (T1961, F62, housewife)'. Family ties are expected to endure even if there is only infrequent contact: ' $I$ always feel a sense of belonging with family, even those I don't see very often.' (V3773, F47, co-habiting, NHS 
pharmacy senior ATO). Family is thus presented as a taken-for-granted source of belonging, the permanence of which need not be explained. Instead, family relationships that have grown distant require explanation, such as a family member's 'inability to cope and be supportive' in times of crisis (P3213, F44, married, housewife/mother/volcanologist). Permanence does not however mean that family belonging is necessarily without ambivalence. This is exemplified by one writer who notes that despite knowing that 'I will always belong to the family I grew up in', she still feels that 'I haven't, in many other respects, felt that I belonged there' because she has 'always felt a bit different, a bit of an outsider' due to her 'views and perspectives on life' (A2801, F44, single, unable to work due to long-term illness).

In contrast to family belonging, the MOP accounts indicate that belonging to friends is something that is expected to undergo change: 'of course [some] friends come and go' (P2957, F41, married, local government employee, emphasis added). This is not surprising given the common assumption in Britain that whereas family is given, friends are chosen (Spencer \& Pahl, 2006). When it comes to friends, then, it is enduring belonging that requires explanation. The MOP writers tell us that such bonds are not only based on familiarity and a similarity in terms of values and interests, but also mutual care, support and acceptance. Friendships to 'those who are known and accepted by us' (M4369, M38, married, foster carer) and who 'like me and ... think of me' (F4395, M47, single, British Council officer) endure, as do relationships to friends 'who display consistency and common values' (B4290, F40, married, freelancer). Enduring friends turn to each other for emotional support and, over the course of a lifetime, come to know each other intimately: 'We have little to hide from each other as during the years we have become familiar with each other's ups and downs, good and bad points' (L1991, F73, widow, retired nurse/civil servant). Thus, though culturally conceived of as less stable than family, such intimate friendships can in fact be experienced as offering enduring reciprocal emotional support that for some can be lacking in their family relationships (Cronin, 2015b). 
Enduring friendships entail not only that such consistent qualities of a friendship continue to be experienced (cf. Coleman, 2008: 97) but also that the future feels 'known' and certain. One writer imagines 'sharing a lot of our lives together' with her four closest friends (C3210, F20s). What is striking in such statements is the certainty with which the future is predicted: ' I know that we will always be friends' (F4395, M47, single, British Council officer). Proclamations of this kind exemplify the ways in which 'present and past are experienced as a function of what will be' and therefore act not only as a summary of a life lived so far, but also as a prophecy (Carr, 1991: 29; Bruner, 1990: 121). They vividly evoke possible future selves that 'reflect personal concerns of enduring salience and investment' - but what is more important, they also 'provide an evaluative and interpretive context of the current view of self' (Markus \& Nurius, 1986: 955). In other words, these accounts of enduring past and future belonging are used to say something about the moral character of the self, because enduring ties are testament to a self who remains loyal to friends and does not forsake them, and who is not forsaken by her or his friends, even when the relationship becomes difficult (Smart et al., 2012). The MOP accounts depict enduring friendships as particularly important in this regard, perhaps because these, unlike family ties, cannot be taken as given. As noted above, presenting oneself as moral is important if the social self is to be able to claim belonging to her or his social group.

While the MOP writers portray enduring bonds as based on all-encompassing intimate knowledge of a person, temporary relational belonging is depicted as based on only one aspect that is bound by context and easily disturbed by the passage of time. One that is most commonly named is a sense of belonging to colleagues in the workplace, described by one writer as a 'false intimacy', which can 'soon dissipate once you have left a job' because 'nothing [is] left in common once the shared intimacy [is] gone' (P2957, F41, married, local government employee). While many respondents in Cronin's (2014) study on friendship depicted work friendships as having the potential for an intensity not found in other friendships, the MOP writers indicate that nevertheless, friendships made at work run a high risk of fading because the source of the connection is 'the work 
not actually a real friendship' (H3821, M58, married, teacher). The use of the word 'real' in the previous excerpt is noteworthy because it signals the evaluative distinction between permanent belonging as 'real' and authentic, and fleeting belonging as superficial or even false.

But the MOP writers do not explain why this distinction between enduring and fleeting bonds is important, perhaps because this is so taken for granted. I propose that we can begin to answer this question by looking at Western notions of the self and the functions of autobiographical narrating. First, the distinctions that the MOP writers draw between 'authentic' relationships with family and friends that endure and 'superficial' relationships with less intimate people that fade away brings to mind Miller's (2010) work on how Westerners have come to value the perceived authenticity of the 'true' self, which is seen to lie deep inside a person, over what they see as superficial, that is, that which lies on the surface. The 'true' self is understood as something inherent that cannot fundamentally be altered by time or circumstance, and it is this self that is revealed in enduring relationships. In contrast, the MOP writers' depiction of fleeting relationships seem to only involve the superficial 'social' self that is acquired through socialisation, and consequently cannot be used to judge who a person 'really' is. In other words, the short-term nature of these relationships does not reflect negatively on the moral character of the people involved.

The second reason for why the distinction between authentic and superficial relationships is so significant is that it aids in one of the key aims of telling autobiographical stories, namely evaluating the self through 'moral assumptions and ethical convictions' (Brockmeier, 2000: 59; Bruner, 1990: 121; May, 2008). A central assumption in Western cultures is that a moral person should possess a core identity or 'true self' that remains unchanged through time (Chandler, 2000: 212). Yet the enduring self presents a paradox, given that our selves are in 'a perpetual state of becoming' (Chandler, 2000: 211; Nelson, 2000). One strategy for resolving this paradox is to tell stories where change does not threaten our sense of coherence. The distinction between enduring and fleeting relationships allows MOP writers to do precisely this. Fleeting relationships tell about 
change, but they do not weaken the MOP writers' ability to tell self-narratives that depict their present self as a continuation of their past self, exactly because they distinguish between these fleeting relationships that speak to the social self and enduring relationships that reflect a 'true' self (Mason-Schrock, 1996; Bruner, 1987). Bennett (2015: 5) notes that a sense of continuity can be created by invoking the trope of authenticity which 'embodies continuity through time'. One way of establishing this sense of continuity is by reference to enduring relationships as authentic. In doing so, the MOP writers are signalling their own constancy of character, the corner-stone upon which a stable self-image can be constructed (Bruner, 1991).

\section{Belonging out of time}

So far, I have explored ways of talking about enduring belonging that are clearly tied to the passage of time, and where the number of years a relationship has lasted is used to signal the moral, linear and unitary character of the self. But there are also forms of enduring belonging that seem, in the telling at least, to be experienced 'out of time', two of which are explored here: encountering the sense of 'time falling away' when reunited with old friends, and a sense of belonging to places to which one has ancestral connections. These accounts describe what Mason (2008: 37) has called 'ethereal affinities' that are mysterious and magical, 'considered beyond (rational) explanation'. I propose that these forms of belonging gain their mysterious and inexplicable character from the fact that they go against the expected norm, namely that belonging to people who are not family requires regular contact (Cronin, 2015a: 676) and that belonging to place is based on living there (Edwards, 2000).

Friendships that stand the test of time despite lack of regular contact receive detailed attention in the MOP accounts: 'you know this group is unbreakable, and you just pick up from where you left off, probably because you have so much history together, you're always part of each 
other's lives' (A1706 F64, married, artist/ward clerk). It is in moments such as these that we can glimpse the relational, distributed or even trans-subjective self in connection, in the 'in-between state of being within and without our selves' (Game, 2001: 154, 155). Just like the respondents in Cronin's (2015a: 676-677) study, the MOP writers seem to find such connections that endure despite lack of co-presence to be exceptional, even puzzling, and as going counter to ordinary experiences of time. The notion of 'picking up from where we last left off' (M4369, M38, married, foster carer) is a commonly known one, to the point of being an archetypal experience. Game (2001: 155) speaks of archetypal experiences as having mythic qualities, one of which is that they are experienced as extra-temporal. Indeed, the closest friendships are described as untouched by time by the MOP writers: 'it feels like it was only yesterday we spoke' (S4626, F42, married, ER consultant). Even after a gap of years, it is possible to 'carry on a continuing conversation about anything, from the trivial to the momentous' (M2164, F83, widow, retired biologist). These examples speak to a strong bond that once forged, can lay dormant, but is easily brought back to life by reunions: 'the old sense of fellowship and belonging was at once there and the years fell away' (B2710, M80, married, retired clergyman). As Cronin (2015a: 678) remarks, a strong emotional connection can transform how people experience time such that past and present are folded together. It is as though the intervening years have not taken place; time is telescoped in such a way that past experiences and past feelings become palpably actualised in the present - they are a living past (Brockmeier, 1995; Coleman, 2008).

Another form of timeless belonging is expressed in relation to belonging to places where the MOP writers have ancestral roots. This is best exemplified by those accounts where the writers talk of places where they have never resided, yet have felt very much at home in, even before knowing of their ancestral link to the place. One writer describes her initial sense of belonging as having 'no apparent reason' (S4626, F42, married, ER consultant). It was only after she investigated 'some family history through the female line' that she learnt that the previous six generations had all been born in the same area, which she offers as an explanation for 'why I like [county] so much as it feels 
like home'. Kramer (2011: 390) has proposed that finding a genealogical link to place allows people to 'claim belonging where ordinarily they would not "fit"'. The following writer recounts a similar experience, of 'for some reason' having always felt 'at home' in areas from where 'many of my ancestors on my mother's side of the family came', a fact she was unaware of until she conducted 'research into my family tree'. This same writer wonders whether 'a sense of belonging is partly genetic' (W1813, F59, married, retired teacher).

By describing their sense of belonging as having no rational explanation, these two writers are alluding to the common perception that belonging to place is usually forged by living there (Edwards, 2000). They suggest that perhaps belonging can be passed down the blood, but do so only cautiously, probably because they are aware that current scientific knowledge on genetics is unlikely to support such theories. Nevertheless, they use their genetic links to place as a 'folk theory' (Bruner, 1990) that helps to explain the seemingly inexplicable. Such a fundamental connection to place that is part of one's genetic make-up is timeless because it has no clear temporal point of origin and cannot be touched by time - it exists there always, even if at times dormant, for as long as the genetic line survives (cf. Mason, 2008: 34). These references to past generations are reminiscent of Nelson's (2000: 183) notion of the self as 'a continuing self in time, from an unremembered birth to an unimagined adulthood, and beyond this to generations and other peoples past and future'. Kramer (2011: 386, 392) has also noted that genetic links offer people a sense of 'belonging in time' and 'connectedness across the generations' as well 'certainty of meaningfulness in the future, even immortality'.

These two forms of belonging that appear timeless - an enduring sense of belonging to friends whom one does not see regularly and the feeling of having genetic roots in a place one has not lived in - are clearly noteworthy, surprising or even inexplicable to the MOP writers and thus help to highlight how enduring belonging is 'supposed to' be anchored in time. Instead of being able to refer to the chronological flow of everyday life that brings familiarity and ease, the writers must 
resort to surreal or magical temporalities in order to explain why these belongings have endured. Game (2001: 158) argues that it is in the moments when we experience a sense of connectedness with the archetypal or archaic that we can forget our selves and that we are most alive and at home, which perhaps helps explain why for the MOP writers, these forms of timeless belonging have clearly had such a profound effect.

It is here that I return to Bergson's (2001[1889]) distinction between a superficial self that experiences time and a passionate self that is in touch with duration. I suggest that when we present ourselves as linear and coherent, we are performing the superficial self that conforms to social conventions, 'lending itself much better to the demands of social life ... and language' (Bergson, 2001[1889]: 128). In contrast, the passionate self is experienced as somehow puzzling and difficult to explain exactly because it pertains to a domain of experience that is akin to pure duration, that is, direct experience that has not yet been rendered linear and logical by fixing it in words. The belonging that is experienced by this passionate self has an extra-temporal quality in that it takes place beyond time understood as the linear passage of days, months and years. Instead, time is experienced in a non-linear fashion to the point that it gains a mythic quality: 'profane time and duration' are suspended in such a way that now and then become the same (Game, 2001: 155). Timeless experiences of belonging also defy notions of the self as temporally linear and singular (cf. Game, 2001: 154) and bring to light the 'distributed self' that is not only distributed across relational ties contained within its biography or across space (Bruner, 1990; Cronin, 2015a), but also across past and future generations. Thus some forms of enduring belonging - and by association the self of a more mythical if not magical variety, can be experienced as timeless, even eternal.

\section{Conclusions}


The starting point for this paper is that belonging is a fundamentally temporal experience. The analysis of 62 Mass Observation Project (MOP) accounts focused on two dimensions of duration: the difference between enduring and fleeting belonging the duration of which can be measured with the help of social time-keeping conventions, and belonging that endures in a timeless fashion. This paper helps fill a notable gap in the belonging literature that has not sufficiently explored temporal aspects of belonging as they are experienced by individual selves. Further, this paper contributes to the literature on temporal and narrative selves by increasing our understanding of how belonging in its various temporal forms contributes to or counteracts the construction of a coherent self.

I argue that the temporality of belonging aids in constructing a changing yet coherent self over time and thus speaks to a person's moral character. The MOP accounts show that enduring family relationships are taken for granted in that no explanation is required for the permanence of the bond. In contrast, enduring friendships are worthy of note, indicating that friendship is not seen as inherently permanent (cf. Spencer \& Pahl, 2006). It then follows that the duration of friendships is normatively evaluated in terms of what it says about the self. Enduring belonging to friends in particular, I argue, is one way that allows us to experience and express a coherent and consistent self that is so highly valued in Western cultures (Young, 1988; Bruner, 1990). Lasting friendships demonstrate that the essential characteristics of a person have not changed and also help establish the moral character of the person as someone who remains faithful to their friends and to whom friends wish to remain faithful in return (Smart et al., 2012). But the varying duration of friendships also allows the MOP writers to solve the paradox of having to display simultaneous change and selfsameness of character. Temporary belongings, because superficial, are merely seen to reflect the inevitable changes that our lives go through, changes that do not say anything about the 'true' self.

Research on belonging tends to depict belonging according to a linear chronological logic, just as the one reflected in the MOP writers' evaluations of the duration of relational belongings as measured in months and years. Attending to belonging as temporal brings forth also another kind of 
temporality, one that is not chronologically linear. Even these ostensibly linear temporalities can be experienced in a non-linear fashion whereby the past retains sense of vitality in the present in the form of a living past (Coleman, 2008). In addition, the MOP writers describe experiences of belonging that can best be described as timeless or taking place out of time, that defy understandings of linear temporality and a singular coherent self and that help connect people with a sense of timeless time or even eternity. Some enduring belongings gain their own temporality: either they are not affected by time or their temporal origin is unclear. Such timeless belongings necessitate further explanation because they challenge the cultural norms surrounding relational and place belonging. The MOP writers appear mystified by the strength of feelings of belonging that can be evoked by friendships that seem untouched by the passage of time and by unfamiliar places. These are examples of ethereal affinities that resist rational explanation (Mason, 2008). What these accounts tell us is that, contrary to Western notions of the unitary and bounded self, there are instances when the self and its connections to the world are experienced not only as fundamentally relational but also as expanding beyond the lifetime of the person. The self is thus distributed both across its relationships and across time. By exploring how MOP writers make sense of the temporality of belonging in relation to their self, this paper offers a contribution to the literature on time because it reveals a rich tapestry of temporalities (linear, cyclical, timeless and eternal) which together make up a complex experience of duration.

Given the social nature of how we perceive time, it is likely that the findings of this paper are not straightforwardly applicable to other samples. There are cultural differences regarding how the self and its relationships, as well as time, are viewed and valued. Many of the MOP writers had experienced geographical mobility - and some also social mobility - which inevitably will have had an effect on their temporal experiences of belonging compared to those who have stayed put. The accounts also do not tell us how severe deprivation or discrimination might affect how belonging is experienced through time or indeed which sources of belonging can endure. Thus whenever the temporal nature of belonging is researched, issues such as cultural notions of self, time and 
relationships, access to resources, and social and geographical mobility must be taken into account. Nevertheless, I hope that this paper has convinced the reader of the significance of attending to the temporal aspects of belonging because of what this can tell us about how the self is constructed in time and about how time is experienced. The significance of these findings is in helping us gain a better understanding for how human experiences of time, their sense of belonging and the self are interrelated.

\section{Acknowledgments}

I would like to express my gratitude to the MOP writers who have so generously shared their personal experiences of belonging and to the Trustees of the Mass Observation Archive, University of Sussex for permission to use quotations from the Mass Observation Project material. My sincere thanks also go to Kinneret Lahad for her invaluable comments on an earlier version of this paper, and to the two anonymous reviewers for their helpful suggestions for improvement.

This research received no specific grant from any funding agency in the public, commercial, or notfor-profit sectors.

\section{References}

Antonsich M (2010) Searching for belonging: An analytical framework. Geography Compass 4(6): 644-659.

Bamberg M (2012) Why narrative? Narrative Inquiry 22(1): 202-210.

Bastian M (2014) Time and community: A scoping study. Time \& Society 23(2): 137-166. 
Becker G (1999) Disrupted Lives: How People Create Meaning in a Chaotic World. Berkeley, CA: University of California Press.

Bennett J (2015) Narrating family histories: Negotiating identity and belonging through tropes of nostalgia and authenticity. Current Sociology. Epub ahead of print DOI: 10.1177/0011392115578984. Bergson H (1988[1896]) Matter and Memory (trans. NM Paul \& WS Palmer). Brooklyn, NY: Zone Books.

Bergson H (2001[1889]) Time and Free Will: An Essay on the Immediate Data of Consciousness (trans. FL Pogson). Mineola, NY: Dover Publications.

Binaisa N (2011) Negotiating 'belonging' to the ancestral 'homeland': Ugandan refugee descendents 'return'. Mobilities 6(4): 519-534.

Brockmeier J (1995) The language of human temporality: Narrative schemes and cultural meanings of time. Mind, Culture, and Activity 2(2): 102-118.

Brockmeier J (2000) Autobiographical time. Narrative Inquiry 10(1): 51-73.

Bruner J (1987) Life as narrative. Social Research 54(1): 11-32.

Bruner J (1990) Acts of Meaning. Cambridge, MA: Harvard University Press.

Bruner J (1991) Self-making and world-making. Journal of Aesthetic Education 25(1): 67-78.

Bönisch-Brednich B and Trundle C (eds.) (2010) Local Lives: Migration and the Politics of Place. Farnham: Ashgate.

Carr D (1991) Time, Narrative and History. Bloomington, IN: Indiana University Press.

Chandler M (2000) Surviving time: The persistence of identity in this culture and that. Culture \& Psychology 6(2): 209-231. 
Coleman R (2008) 'Things that stay': Feminist theory, duration and the future. Time \& Society $17(1)$ : $85-102$.

Cronin AM (2014) Between friends: Making emotions intersubjectively. Emotion, Space and Society 10: 71-78.

Cronin AM (2015a) Distant friends, mobility and sensed intimacy. Mobilities 10(5): 667-685.

Cronin AM (2015b) Gendering friendship: Couple culture, heteronormativity and the production of gender. Sociology 49(6): 1167-1182.

Cwerner SB (2000) The chronopolitan ideal: Time, belonging and globalization. Time \& Society 9(2/3): 331-345.

Deleuze G (1988[1966]) Bergsonism (trans H. Tomlinson and B. Habberjam). New York: Zone Books.

Edwards J (2000) Born and Bred. Oxford: Oxford University Press.

Flaherty MG (1993) Conceptualizing variation in the experience of time. Sociological Inquiry 63(4): 394-405.

Flaherty MG (2002) Making time: Agency and the construction of temporal experience. Symbolic Interaction 25(3): 379-388.

Fenster T (2004) Belonging, memory and the politics of planning in Israel. Social \& Cultural Geography 5(3): 403-17.

Fortier A-M (2000) Migrant Belongings: Memory, Space, Identity. Oxford: Berg.

Game A (2001) Belonging: Experience in sacred time and space. In May J and Thrift N (eds.) Timespace: Geographies of Temporality. London: Routledge, pp. 226-239. 
Gergen K and Gergen MM (1983) Narratives of the self, in Sarbin TR and Scheibe KE (eds.), Studies in social identity. New York: Praeger.

Golden D (2002) Belonging through time: Nurturing national identity among newcomers to Israel from the former Soviet Union. Time \& Society 11(1): 5-24.

Guerlac S (2006) Thinking in Time: An Introduction to Henri Bergson. Ithaca, NY: Cornell University Press.

Jelinek EC (1986) The Tradition of Women's Autobiography: From Antiquity to the Present. Boston, MA: Twayne Publishers.

Kramer A-M (2011) Kinship, affinity and connectedness: Exploring the role of genealogy in personal lives. Sociology 45(3): 379-395.

Markus H and Nurius P (1986) Possible selves. American Psychologist 41(9): 954-969.

Mason J (2008) Tangible affinities and the real fascination of kinship. Sociology 42(1): 29-45.

Mason-Schrock D (1996) Transsexuals' narrative construction of the 'true self'. Social Psychology Quarterly 59: 176-192.

May V (2008) On being a 'good' mother: The moral presentation of self in written life stories. Sociology 42(3): 470-486.

May V (2011) Self, belonging and social change. Sociology 45(3): 363-78.

May V (2013) Connecting Self to Society: Belonging in a Changing World. Basingstoke: Palgrave Macmillan.

May V (N.d.a) "Each decade alters your sense of belonging": Belonging across the lifetime', unpublished manuscript submitted for publication to British Journal of Sociology. 
May V (N.d.b) Belonging from afar: Nostalgia, time and memory, unpublished manuscript submitted for publication to Sociological Review.

Mead GH (1932) The Philosophy of the Present. Chicago, IL: University of Chicago Press.

Mead GH (1934) Mind, Self, \& Society: From the Standpoint of a Social Behaviorist. Chicago, IL:

University of Chicago Press.

Miller L (2003) Belonging to country - A philosophical anthropology. Journal of Australian Studies 27(76): 215-23.

Miller D (2010) Stuff. Cambridge: Polity.

Monteiro B (2015) Nostalgia and the social perception of the past: The ethnographic revisit of an industrial community (1980 and 2010). Time \& Society. Epub ahead of print DOI:

$10.1177 / 0961463 \times 15577272$.

Muldoon MS (2006) Tricks of Time: Bergson, Merleau-Ponty and Ricoeur in Search of Time, Self and Meaning. Pittsburgh, PA: Duquesne University Press.

Nelson K (2000) Narrative, time and the emergence of the encultured self. Culture \& Psychology 6(2): 183-196.

Passerini L, Lyon D, Capussotti E and Laliotou I (eds.) (2007) Women Migrants from East to West: Gender, Mobility and Belonging in Contemporary Europe. New York and Oxford: Berghan Books.

Ramírez C (2014) 'It's not how it was': The Chilean diaspora's changing landscape of belonging. Ethnic and Racial Studies 37(4): 668-684.

Ricoeur P (1981) Narrative time. In Mitchell WJT (ed.) On narrative. Chicago, IL: University of Chicago Press, pp. 165-186. 
Sayer D (2004) Incognito ergo sum: Language, memory and the subject. Theory, Culture \& Society 21(6): 67-89.

Sheridan D (1993) Writing to the Archive: Mass-Observation as autobiography. Sociology 27(1): $27-$

40.

Smart C, Davies K, Heaphy B and Mason J (2012) Difficult friendships and ontological insecurity. Sociological Review 60(1): 91-109.

Spencer L and Pahl R (2006) Rethinking Friendship: Hidden Solidarities Today. Princeton, N.J.:

Princeton University Press.

Taylor S and Wetherell M (1999) A suitable time and place: Speakers' use of 'time' to do discursive work in narratives of nation and personal life. Time \& Society 8(1): 39-58.

Young M (1988) The Metronomic Society: Natural Rhythms and Human Timetables. London: Thames and Hudson.

Yuval-Davis N (2011) The Politics of Belonging: Intersectional Contestations. London: Sage.

Wood N and Waite L (2011) Editorial: Scales of belonging. Emotion, Space and Society 4(4): 201-202.

$\varnothing i a n$ H (2004) Time out and drop out: On the relation between linear time and individualism. Time \& Society 13(2/3): 173-195.

\footnotetext{
${ }^{i}$ Each MOP writer is given a unique identifier, consisting of a letter and number combination. I also indicate the gender of the writer ( $\mathrm{M}$ for male, $\mathrm{F}$ for female), followed by age, family status and occupation if these are known. Place names have been omitted to protect the anonymity of the writers. All extracts are true to the original, typographical and grammatical errors included.
} 